\title{
KENDALA GURU PAUD \\ MENGEMBANGKAN SENTRA MEMBACA DAN MENULIS (STUDI KASUS DI JAKARTA TIMUR)
}

\author{
Yubaedi Siron ${ }^{1}$ \\ ${ }^{1}$ UIN Syarif Hidayatullah, Jakarta
}

\begin{abstract}
Early childhood is the important stage in entire human life-span. Early writing and reading in early childhood is the one of critical aspect to be developed. Teachers should improve the environment which support children in literacy. The objective of this study is to describe the obstacles of early childhood teachers to develop reading and writing center for the children. This study used qualitative method which involved 27 early childhood teachers in East Jakarta. Purpossive sampling method was used, while data analyze used Miles and Huberman technique to data reduction, data display, and verification. This study revealed the experience of early childhood teacher obstacles to develop reading and writing center. It included the obstacle of preparing media of reading and writing, difficultes to manage play environment, improve library center, creating an appropriate book for children, and developing media for listening activities.

Keywords: reading and writing center, teacher obstacles, early childhood education.
\end{abstract}

\begin{abstract}
Abstrak: Usia dini merupakan fase penting dalam kehidupannya. Membaca dan menulis permulaan untuk anak usia dini sebagai salah satu aspek penting untuk dikembangkan. Guru sebaiknya mengembangkan lingkungan yang mendukung literasi anak usia dini. Tujuan penelitian ini untuk mendeskripsikan kendala guru PAUD dalam mengembangkan sentra membaca dan menulis. Penelitian ini menggunakan metode kualitas dengan melibatkan 27 guru PAUD di Jakarta Timur. Metode pengambilan data menggunakan purposive sampling dan menggunakan analisis Miles and Huberman untuk mereduksi data, mendisplay data dan memverifikasi data. Penelitian ini mengungkapkan bahwa guru PAUD di Jakarta Timur mempunyai kendala dalam mengembangkan sentra membaca dan menulis. Kendala ini meliputi kendala dalam menyiapkan media membaca dan menulis, kendala dalam memanajemen lingkungan bermain, kendala dalam mengembangkan sentra perpustakaan anak, mengembangkan buku yang sesuai dengan tahapan perkembangan anak, dan mengembangkan media untuk kegiatan mendengarkan bagi anak
\end{abstract}

Kata Kunci: Sentra membaca dan menulis, Kendala guru, PAUD.

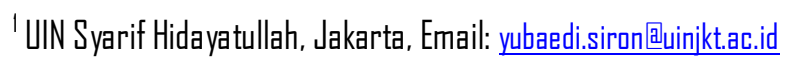

142 Cakrawala Dini: Vol. I0 No. 2, November 2019 


\section{PENDAHULUAN}

Masa usia dini merupakan fase kritis kehidupan manusia. Begitu juga tahapan-tahapan literasinya. Pengembangan literasi di Indonesia perlu ditingkatkan. Pada level usia yang lebih tinggi, indeks literasi membaca anak Indonesia masih menyedihkan, hanya naik satu poin: 396 pada 2012 dan 397 pada 2015. (OECD 2016)

Literasi menjadi salah satu skill yang perlu dikembangkan untuk menghadapi revolusi industri 4.0. Konsep literasi merupakan suatu kontinum yang dinamis, yakni mulai dari kemampuan membaca, kemudian membaca dan menulis, berpikir kritis dan berbahasa lisan yang bergerak mengikuti zaman dan dimanfaatkan untuk belajar sepanjang hayat baik di rumah, di tempat kerja, maupun dalam masyarakat (Unesco 2006).

Guru PAUD sebagai ujung tombak pendidikan, harus bisa mengembangkan literasi anak usia dini. Sejauh ini, di Indonesia masih jarang penelitian yang relevan tentang bagaimana tantangan guru dalam mengembangkan sentra membaca dan menulis anak usia dini (Basyiroh 2017). Belum lagi guru juga masih kesulitan untuk memfasilitasi anak-anak berkebutuhan khusus dalam mengembangkan literasi yang ada di sekolahnya (Siron 2018).

Praktiknya, banyak guru-guru yang menyalahi tahapan perkembangan ketika mengajarkan calistung untuk anak usia dini (Christianti 2013) Ini akan menjadi fatal ketika calistung dipaksakan pada anak. Karena perkembangan bahasa anak usia dini masih sangat fluktuatif (White, 2005; Justice \& Sofka, 2010). Bahkan ada beberapa anak, secara ekspresif pengucapan kalimat saja belum begitu jelas (Siron 2016), apalagi tahapan kemampuan berbahasa yang lebih tinggi seperti membaca dan menulis. Pemaksaan membaca dan menulis terlalu dini akan berdampak negatif pada perkembangan anak di fase berikutnya. (Painter 1999)

Penelitian ini bertujuan untuk mengungkap kendala yang dialami guru PAUD di Jakarta Timur dalam mengembangkan sentra membaca dan menulis untuk anak usia dini. Jakarta Timur dipilih menjadi objek penelitian karena Jakarta Timur merupakan daerah yang mempunyai wilayah terluas di DKI Jakarta. Dengan karakteristik guru yang beragam, Jakarta Timur dijadikan sebagai latar yang unik dan perlu digali.

Penelitian ini dapat dijadikan acuan pengembangan kompetensi guru dalam mengembangkan sentra membaca dan menulis di PAUD.

\section{METODOLOGI PENELITIAN}

Penelitian ini menggunakan metode kualitatif. Data diambil dengan melakukan wawancara semi-terstruktur. Penelitian ini dilakukan pada bulan Maret sampai Mei 2018. Penelitian ini difokuskan pada kesulitan guru PAUD dalam mengembangkan sentra membaca dan menulis, dengan latar penelitian di Jakarta Timur. Data dikumpulkan dengan purpossive sampling dengan melibatkan 23 guru PAUD di 23 sekolah yang berbeda. Data dianalisis menguganakan Miles dan Huberman model yang meliputi reduksi data, penyajian data dan simpulan/verifikasi (Miles \& Huberman 1994)

\section{HASIL PENELITIAN DAN PEMBAHASAN}

Hasil Penelitian

1. Guru Terkendala dalam Pembelajaran Menulis di Kelas

W1, W2, W3, W4, W5, W6, W7, W8, W9, W10, W11, W12, W13, W14, W15, W16, W17, W18, W19, W20, W21, W22, W23

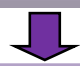

W1, W2, W4, W5, W6, W7, W9, $\mathrm{W} 10, \mathrm{~W} 11, \mathrm{~W} 14, \mathrm{~W} 15, \mathrm{~W} 18$, W20, W21, W19, W17, W22,

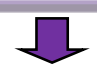


W4, W23, W5, W1, W2, W6, W7, W11, W15, W18, W20, W21, W9, W10, W19, W14, W17, W22

Gambar 1. Proses Pengumpulan Data, Reduksi, dan Penyajian Data tentang Kendala Guru dalam Pembelajaran Menulis di Kelas

Guru belum terlalu memahami kegiatan menulis yang bagaimana pada anak usia 4-5 tahun yang tidak memberatkan anak. Ada beberapa guru belum tahu tahapan menulis anak sesuai usianya (Christianti 2013). Guru masih bingung untuk memberikan kegiatan menulis yang tepat. Guru masih bingung menghadapi anak yang perkembangan motorik halusnya belum matang [W4] [W23]. Guru masih kebingungan memperlakukan anak yang belum mengenal konsep huruf secara keseluruhan [W5] (Rhyner dkk 2009).

Guru mengalami kendala saat kegiatan menulis ketika anak kurang fokus seperti lebih sering melamun dan bercanda [W1]. Guru juga mempunyai kesulitan untuk mengatasi mood anak yang terkadang masih ingin main atau memilih permainan lain dari pada kegiatan menulis [W2].

Guru terkendala ketika menghadapi siswa yang belum bisa pegang pensil [W6] [W7] [W11] [W15] [W18] [W20] [W21]. Masih kurang mandirinya anak untuk melakukan kegiatan menulis. Anak masih butuh bantuan guru untuk memegang alat tulis [W9]. Kurangnya kreativitas guru dalam menciptakan media pembelajaran untuk kegiatan menulis.(Taylor dkk 2011) Beberapa guru masih memfokuskan menggunakan Lembar Kerja (LK) dalam pembelajaran menulis [W10] [W19].

Anak masih terpapar dengan LK yang terlalu banyak sehingga anak kelelahan dalam mengerjakan LK [W14]. Peralatan main yang mendukung pembelajaran menulis kurang mencukupi [W17]. Media dan metode guru lakukan kurang menarik bagi anak itu [W22].

\section{Guru Terkendala dalam Pembelajaran Membaca di Kelas}

W1, W2, W3, W4, W5, W6, W7, W8, W9, W10, W11, W12, W13, W14, W15, W16, W17, W18, W19, W20. W21. W22. W23

$\mathrm{W} 1, \mathrm{~W} 2, \mathrm{~W} 2, \mathrm{~W} 3, \mathrm{~W} 4, \mathrm{~W} 5, \mathrm{~W} 7$, W7, W9, W11, W13, W11, W11, W14, W15, W16, W18, W19, W20, W21, W22, W23.

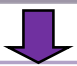

W20, W1, W7, W11, W2, W22, W3, W4, W21, W23, W2, W5, W9, W13, W7, W13, W11, W14, W15, W16, W18. W19

Gambar 2. Proses Pengumpulan Data, Reduksi, dan Penyajian Data tentang Kendala Guru dalam Pembelajaran Membaca di Kelas

Anak belum mengenal keaksaraan [W20]. Dalam pembelajaran membaca beberapa anak ada yang belum terlalu hafal huruf dan sulit untuk mengeja [W1][W7][W11]. Tidak jauh berbeda dengan kegiatan menulis, kegiatan membacapun sama, kurangnya fokus dari anak tersebut [W2][W22]. Media, metode dan strategi yang digunakan guru monoton sehingga anak bosan [W3][W4][W21] [W23]. Masih banyak anak yang belum tumbuh minat untuk membaca permulaan [W2][W5][W9][W13]. Beberapa orang tua anak tidak mengenalkan membaca dikarenakan sibuk bekerja [W7]. Kegiatan membaca hanya kepada guru dan pihak sekolah saja padahal lingkungan juga memengaruhi minat membaca anak [W13]. Padahal, keterlibatan orang tua sangat penting dalam perkembangan literasi anak (Li\& Fleer, 2015; Bae-suh, 2012).

Selain itu, ada anak ABK yang perlu penanganan khusus dan guru tidak tahu bagaimana menanganinya[W11]. Padahal, semua anak berhak untuk 
mengikuti proses pembelajaran tanpa terkecuali (Siron 2018). Guru masih kebingungan bagaimana cara agar anak dapat menerima materi membaca dengan baik dan dengan metode seperti apa agar anak semangat membaca [W14].

$\begin{array}{clr}\text { Guru } & \text { kesulitan } & \text { dalam } \\ \text { mengenalkan } & \text { huruf-huruf } & \text { yang }\end{array}$ simbolnya hampir sama seperti huruf $b$, $\mathrm{d}, \mathrm{m}, \mathrm{n}$, sehingga anak terkadang tertukar dalam penyebutannya dan begitu pula dengan penulisannya [W15]. Guru terkendala dalam menangani anak yang baru mengenal abjad [W16]. Guru kurang paham akan tahapan keaksaraan awal pada anak [W18]. Guru dilematis akan keinginan orang tua yang menginginkan anaknya bisa baca di sekolah yang tidak sesuai dengan tahap perkembangannya, dan juga pendidikan orang tua yang minimal [W19].

\section{Guru Terkendala untuk Mengembangkan Sentra Membaca/ Menulis}

Guru terkendala sarana dan prasarana yang belum memadai. Ruangan dan fasilitas yang kurang memadai ketersediaan buku anak masih kurang, alat-alat permainan yang berkaitan dengan calistung masih kurang [W1] [W3] [W6] [W18]. Ruangan di sekolah yang terbatas [W7][W9][W21] [W10][W13] [W19], alat dan media yang ada di sekolah juga belum terlalu banyak. Banyak guru yang masih belum paham cara mengembangkan sentra [W4] Padahal, sarana dan prasarana yang baik adalah syarat mutlak kualitas pembelajaran yang baik di PAUD. (Tayler dkk, 2013)

W1, W2, W3, W4, W5, W6, W7, W8, W9, W10, W11, W12, W13, W14, W15, W16, W17, W18, $\mathrm{W} 19, \mathrm{~W} 20, \mathrm{~W} 21, \mathrm{~W} 22, \mathrm{~W} 23$

W1, W3, W6, W18, W7, W9, W21, W10, W13, W19, W4, W11, W20, W12, W13, W14, W17
W1, W3, W4, W6, W7, W9, W10, W11, W12, W13, W13, W14, W17, W18, W19, W20, W21

Gambar 3. Proses Pengumpulan Data, Reduksi, dan Penyajian Data tentang Kendala Guru dalam Mengembangkan Sentra Membaca dan Menulis.

Guru perlu menyiapkan alat/bahan untuk membaca dan menulis supaya anak minat baca dan menulis [W11][W20]. Guru belum menciptakan kegiatan yang beragam dan menarik sehingga anak senang di sentra membaca dan menulis[W12][W13]. Guru belum melibatkan anak dalam penyiapan buku dan alat kegiatan membaca/menulis [W14] Alat main yang menunjang kegiatan membaca masih kurang memadai[W17].

4. Guru Mendapat Masalah dalam Menyiapkan Media di Sentra Kegiatan Membaca dan Menulis.

W1, W2, W3, W4, W5, W6, W7, W8, W9, W10, W11, W12, W13, W14, W15, W16, W17, W18, W19, W20, W21, W22, W23

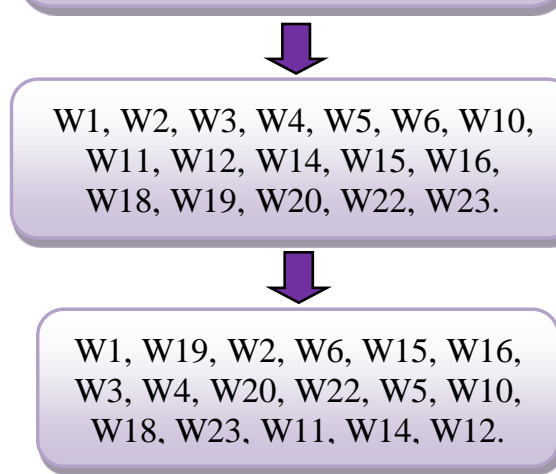

Gambar 4. Proses Pengumpulan Data, Reduksi, dan Penyajian Data tentang Masalah Guru dalam Menyiapkan Media di Sentra Kegiatan Membaca dan Menulis.

Masalah yang dihadapi guru dalam menyiapkan media, guru belum mampu memilih dan menciptakan media yang tepat [W1] [W19]. Guru masih kurang kreativitas dan pengetahuan dalam membuat media untuk kegiatan 
anak [W2] [W6] [W15] [W16]. Apabila ingin membuat media, biasanya dari uang guru sendiri, media yang beli di toko beberapa harganya cukup mahal dan guru belum tahu cara penggunaannya [W3]. Guru kehabisan ide untuk menyiapkan kegiatan pembelajaran yang variatif untuk anak [W4] [W20].

Waktu penyiapan yang kurang [22]. Buku kurang bervariasi/ kurang menarik [W5]. Fasilitas sarana dan prasarana di sekolah yang kurang memadai sehingga guru tidak dapat menyiapkan media pembelajaran dengan maksimal [W10] [W18] [W23]. Kurangnya media dan anak-anak mudah bosan pada mainan yang ada di sekolah. Tempat bermain sekolah kurang memadai [W11] [W14]. Guru kesulitan menghubungkan antara media dengan tema yang sesuai agar anak memahami dan dapat melakukan kegaiatan berdasarkan indikator kemampuan anak [W12]. Padahal keterampilanketerampilan guru tersebut merupakan kunci utamanya. (Tayler dkk, 2013)

\section{Guru Kesulitan dalam Mengelola Lingkungan Bermain di Sentra Membaca/ Menulis}

W1, W2, W3, W4, W5, W6, W7, $\mathrm{W} 8, \mathrm{~W} 9, \mathrm{~W} 10, \mathrm{~W} 11, \mathrm{~W} 12, \mathrm{~W} 13$, W14, W15, W16, W17, W18, W19, W20, W21, W22, W23

$$
\begin{gathered}
\mathrm{W} 1, \mathrm{~W} 2, \mathrm{~W} 3, \mathrm{~W} 4, \mathrm{~W} 5, \mathrm{~W} 5, \mathrm{~W} 6, \\
\mathrm{~W} 7, \mathrm{~W} 8, \mathrm{~W} 17, \mathrm{~W} 18, \mathrm{~W} 21, \mathrm{~W} 13, \\
\mathrm{~W} 14, \mathrm{~W} 15
\end{gathered}
$$

Gambar 5. Proses Pengumpulan Data, Reduksi, dan Penyajian Data tentang Kesulitan Guru dalam Mengelola Lingkungan Bermain di Sentra Membaca/Menulis.

Guru kesulitan dalam pengaturan waktu [W2] [W4]. Guru juga kesulitan dalam mengelola kelas, seperti ruang yang kurang memadai/terlalu sempit, pencahayaan dan sirkulasi udara kurang sehingga ruang agak panas, penataan bahan main kurang tertata rapi karena rak untuk penyimpanan mainan masih kurang [W1] [W3] [W5] [W17] [W18] [W21]. Jumlah buku yang kurang memadai; buku kurang bervariasi/kurang menarik [W5].

Guru juga masih kesulitan dalam mengelola aktivitas anak di kelas [W6] [W7] [W8]. Guru belum paham tentang mengelola dan menata lingkungan di sentra membaca dan menulis. Juga kurangnya pelatihan-pelatihan tentang apa saja kegiatan yang ada di sentra membaca dan menulis [W13]. Guru masih bingung bagaimana cara mengatur peletakan alat bermain yang baik agar dapat melatih kemandirian anak [W14]. Kurangnya rasa kesadaran dalam hal menata atau menjaga sarana dan prasarana sehingga terlihat kurang menarik dan kurang rapi dilihatnya [W15]. Padahal, manajemen merupakan salah satu kunci sukses pembelajaran di PAUD (De Haan dkk, 2014; LaParo dkk, 2012).

6. Kendala guru dalam mengembangkan pojok perpustakaan di sentra membaca dan menulis

W1, W2, W3, W4, W5, W6, W7, W8, W9, W10, W11, W12, W13, W14, W15, W16, W17, W18, W19, W20, W21, W22, W23

$\mathrm{W} 1, \mathrm{~W} 2, \mathrm{~W} 3, \mathrm{~W} 4, \mathrm{~W} 4, \mathrm{~W} 5, \mathrm{~W} 5$, W6, W7, W8, W9, W10, W12, W13,W13, W14, W15, W16, W17, W18, W19, W20, W21, W22, W23.

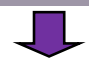

W5, W18, W19, W1, W3, W7, W9, W2, W6, W10, W13, W14, W17, W4, W5, W4, W8, W16, W12, W13, W20, W22, W23, W15, W21

Gambar 6. Proses Pengumpulan Data, Reduksi, dan Penyajian Data tentang Kesulitan Guru dalam 
Mengembangkan Pojok Perpustakaan di Sentra Membaca dan Menulis

Sarana dan prasarana perpustakaan yang belum memadai serta ketersediaan buku masih kurang [W5] [W18] [W19], alat-alat permainan yang berkaitan dengan calistung masih kurang [W1] [W3]. Di lain sisi, etos kerja guru terlihat ketika ruangan yang kurang memadai, tapi guru berusaha bagaimana caranya menyetting kelas agar bisa digunakan untuk perpustakaan walau hanya sedikit [W7] [W9]. Minimnya koleksi buku [W2] [W6] [W10] [W13] [W14] [W17]. Di dalam pojok perpustakaan membutuhkan buku-buku yang bervariasi dan menarik [W4, W5]. Beberapa guru juga mempunyai inisiatif melibatkan orang tua untuk mendonasikan 1 buku cerita, tapi tidak mendapat dukungan [W4].

Guru mendapat kendala dalam merawat buku [W8]. Guru mempunyai persepsi bahwa perawatan dan pemeliharaan buku-buku di perpustakaan menjadi tanggung jawab bersama [W16].

Sekolah kesulitan untuk menyediakan dan menghadirkan buku yang sesuai perkembangan anak [W12]. Padahal buku yang sesuai dengan tahapan perkembangan anak, akan sangat berguna bagi anak. (Caroline BarrattPugh 2000) Selain itu, kurangnya minat peserta didik dalam membaca serta kurang menariknya hiasan-hiasan yang ada di pojok perpustakaan [W13] [W20] [W22] [W23]. Perpustakaan kurang kondusif dikarenakan masih dipakai untuk aktivititas lain secara bersamaan [W15]. Guru juga kesulitan dalam memperbaharui buku-buku setiap minggu supaya anak tidak bosan di pojok perpustakaan dan harus menambah bukubuku baru [W21].

\section{Kendala Guru dalam Membuat Buku yang Sesuai dengan Perkembangan Anak}

W1, W2, W3, W4, W5, W6, W7, W8, W9, W10, W11, W12, W13, W14, W15, W16, W17, W18, $\mathrm{W} 19, \mathrm{~W} 20, \mathrm{~W} 21, \mathrm{~W} 22, \mathrm{~W} 23$

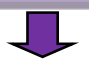

W2, W4, , W5, W5, W5, W6, W6, W8, W9, W10, W11, W13, W13, W14, W14, W15, W16, W17, W18, W19, W20, W21, W22, W23

W2, W4, W10, W13, W19, W5, W18, W23, W5, W6, W5, W6, W14, W16, W17, W11, W20, W8, W13, W22, W9, W15, W21, W14

Gambar 7. Proses Pengumpulan Data, Reduksi, dan Penyajian Data tentang Kendala Guru dalam Membuat Buku yang Sesuai dengan Perkembangan Anak.

Guru masih mempunyai pengetahuan yang kurang untuk mengembangkan buku anak [W2] [W4] [W10] [W13] [W19]. Guru kesulitan untuk memilih isi buku yang menarik dan cocok untuk anak [W5] [W18] [W23]. Guru kesulitan untuk menyusun waktu dalam membuat buku [W5], [W6]; Guru kesulitan menentukan materi yang menarik untuk anak [W5]. Guru kekurangan ide, kurangnya keterampilan menggambar [W6] [W14] [W16] [W17]. Guru kekurangan bahan dan alat untuk membuat buku cerita yang bergambar menarik bagi anak [W11]. Guru mempunyai keterbatasan media/fasilitas yang mendukung [W20].

Bahkan, masih ada guru yang belum punya niatan dan rencana membuat buku [W8] [W13] [W22]. Guru terbatas dengan dana/anggaran [W9] [W15] [W21]. Guru kesulitan cara membuat buku yang menarik, yang tidak membuat anak bosan dan jenuh [W14]. Padahal, buku yang menarik dapat menjadikan anak antusias dan dapat menadi salah satu faktor keberhasilan mengenalkan literasi pada anak (Justice and Sofka 2010). 


\section{Kendala Guru dalam Mengembangkan Media untuk Kegiatan Mendengarkan/Menyimak}

$\mathrm{W} 1, \mathrm{~W} 2, \mathrm{~W} 3, \mathrm{~W} 4, \mathrm{~W} 5, \mathrm{~W} 6, \mathrm{~W} 7$, W8, W9, W10, W11, W12, W13, W14, W15, W16, W17, W18, W19, W20, W21, W22, W23

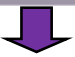

W1, W2, W3, W4, W6, W7, W9, W10, W11, W12, W13, W15, W18, W19, W20, W22, W22, W23

W1, W20, W2, W3, W9, W10, $\mathrm{W} 19, \mathrm{~W} 6, \mathrm{~W} 4, \mathrm{~W} 12, \mathrm{~W} 15, \mathrm{~W} 22$, W18, W22, W23, W7, W11, W13

Gambar 8. Proses Pengumpulan Data, Reduksi, dan Penyajian Data tentang Kendala Guru dalam Mengembangkan Media untuk Kegiatan Membaca/Menyimak

Kurangnya kreatifitas guru dalam mengembangkan media dalam kegiatan menyimak [W1] [W20]. Keterampilan guru dalam mengembangkan kegiatan masih rendah. Anak tidak fokus dalam menyimak karena penyampaian cerita kurang menarik dan memakan waktu yang lama sehingga anak bosan, medianya seperti gambar-gambar dalam buku yang mendukung cerita mungkin dari segi warna dan gambar kurang menarik [W2] [W3] [W9] [W10] [W19] dan kurangnya buku yang sesuai dengan tema [W6]. Guru kesulitan cara untuk membuat media yang menarik sehingga anak fokus dan paham dengan apa yang guru sampaikan [W4] [W12] Variasi media yang disajikan guru masih kurang maksimal sehingga anak dalam menyimak/mendengarkan cepat bosan [W15] [W22]. Guru belum menguasai cara menarik anak yang belum mempunyai ketertarikan dengan media yang guru berikan [W18] [W22] [W23].

Selain itu, kondisi ruangan yang digunakan anak dalam mengembangkan keterampilan menyimak kurang kondusif; Guru masih kesulitan dalam memanajemen kelas dan mengatur anak di kelas [W7] Guru kesulitan dalam mengembangkan kemampuankemampuan bercerita, menulis dan berhitung yang masih belum maksimal [W11]. Tidak adanya fasilitas audio visual yang membuat ketertarikan anak dalam kegiatan mendengar dan menyimak [W13]. Padahal, pengembangan media untuk pembelajaran mendengarkan atau menyimak sangat membantu anak untuk memahami perintah guru (Cheung 2012).

\section{KESIMPULAN}

Penelitian ini disimpulkan bahwa masih banyak kendala-kendala yang dihadapi guru PAUD dalam mengembangkan sentra membaca dan menulis. Kendala-kendala yang dihadapi yaitu guru terkendala dalam pembelajaran membaca dan menulis di kelas; Guru terkendala untuk mengembangkan sentra membaca/menulis; Guru mendapat masalah dalam menyiapkan media di sentra kegiatan membaca dan menulis; Guru kesulitan dalam mengelola lingkungan bermain di sentra membaca/ menulis; Kendala guru dalam mengembangkan pojok perpustakaan di sentra membaca dan menulis; Kendala guru dalam membuat buku yang sesuai dengan perkembangan anak; Kendala guru dalam mengembangkan media untuk kegiatan mendengarkan/menyimak.

\section{DAFTAR PUSTAKA}

Bae-suh, S. 2012. "Parental Perceptions on Parent Involvement in Korea." Asia-Pasific Journal of Research in Early Childhood Education 6(1):2141.

Basyiroh, I. 2017. "Program Pengembangan Kemampuan Literasi Anak (Studi Kasus Best Practice Pembelajaran Literasi Di TK Negeri Centeh Kota Bandung ).” Tunas Siliwangi 3(2):120-34. 
Caroline Barratt-Pugh, Mary Rohl. 2000. Literacy Learning in the Early Years. New South Wales: Allen \& Unwin.

Cheung, R H P. 2012. "Teaching for Creativity: Examining the Beliefs of Early Childhood Teachers and Their Influence on Teaching Practices." Australasian Journal of Early Childhood. Sep2012 37:43-52. Retrieved (http://www.earlychildhoodaustralia .org.au/australian_journal_of_early_ childhood/ajec_index_abstracts/teac hing-for-creativity-examining-thebeliefs-of-early-childhood-teachersand-their-influence-on-teachingpractices.html).

Christianti, M. 2013. "Membaca Dan Menulis Permulaan Anak Usia Dini.pdf." Jurnzl Pendidikan Anak II(2):312-17. Retrieved (http://ojs.umsida.ac.id/index.php/ic ecrs/article/view/1394).

De Haan, A K. E., Ed Elbers, and Paul P. M. L. 2014. "Teacher-and ChildManaged Academic Activities in Preschool and Kindergarten and Their Influence on Children's Gains in Emergent Academic Skills." Journal of Research in Childhood Education 28(1):43-58.

Justice, L M. and Sofka, A. E.. 2010. Engaging Children with Print: Building Early Literacy Skills through Quality Read-Alouds. Retrieved (https://ezp.lib.unimelb.edu.au/login ?url=https://search.ebscohost.com/lo gin.aspx?direct=true $\& \mathrm{db}=$ eric $\& A N$ $=$ ED509905\& site $=$ eds live\&scope $=$ site $\% 5$ Cnhttp://www.g uilford.com/cgi-

bin/cartscript.cgi?page=pr/justice 2 .h tm\&print=1\&cart_id=797435.1612).

LaParo, KM., Maynard, C., Thomason, A., and Catherine S-L. 2012. “Developing Teachers' Classroom
Interactions: A Description of a Video Review Process for Early Childhood Education Students." Journal of Early Childhood Teacher Education 33(3):224-38.

Li, L and Fleer, M. 2015. "Family Pedagogy: Parent-child Interaction in Shared Book Reading." Early Child Development and Care 185(11-12):1944-60.

Miles, M. B. and Huberman, M. 1994. "Qualitative Data Analysis: An Expanded Sourcebook." Evaluation and Program Planning 19(1):106-7.

OECD. 2016. "Programme For International Student Assessment (PISA) Results From PISA 2015. Country Note." PISA 1-8.

Painter, C 1999. Learning through Language in Early Childhood. New York: Continuum.

Rhyner, PM., Haebig E K., and West K. M.. 2009. Understanding Frameworks for the Emergent Literacy Stage.

Siron, Y. 2016. "Analisis Kemampuan Penggunaan Kata Kerja Pada Anak Usia 5 Tahun." Jurnal Pendidikan Anak 5(2):848-56.

Siron, Y. 2018. "Implementing Inclusive Education: What Are Elementary Teacher Obstacles? Case Study in East Jakarta , Indonesia." 153(Icddims 2017):177-80.

Tayler, C, Ishimine, Cloney, K., \& Cleveland, GordonThorpe, Karen. 2013. "The Quality of Early Childhood Education and Care Services in Australia." Australasian Journal of Early Childhood 38:1321. 9p. 4 Charts.

Taylor, Jt B., Branscombe, N A, Burcham, J. G., and Land, L.. 2011. Beyond Early Literacy: A Balanced Approach to Developing the Whole Child. New York: Routledge. 
Unesco. 2006. Understandings of Literacy.

White, Hilary. 2005. Developing Literacy Skills in the Early Years: A Practical Guide. 